\title{
Estimating the normal duration using normal Production Rate per Day (PRPD) of project activity
}

\author{
Fachrurrazi Fachrurrazi1,*, Abdullah Abdullah' ${ }^{1}$, Yuwaldi Away², and Teuku Budi Aulia ${ }^{1}$ \\ ${ }^{1}$ Syiah Kuala University, Department of Civil Engineering and Doctoral Program of Engineering, Indonesia-Aceh \\ ${ }^{2}$ Syiah Kuala University, Department of Electrical Engineering, Indonesia -Aceh
}

\begin{abstract}
A Project Estimator cannot claim that his/her estimated duration is better than others. They can determine the reasonable duration based on deterministic and probabilistic factors affecting the duration and then specify how to achieve it. This condition provides an overview that the activity duration changeable stochastically as a result of uncertainty-factors. However, we have a presumption that the activities duration will be normally distributed based on variation of its production rate per day (PRPD). The purpose of this study are (i) estimating the normal duration of the project activities using PRPD; and (ii) conducting the hypothesis testing for the PRPD normality of the project activities in South of Aceh. Hypothesis testing toward six-activities from 50 projects in South of Aceh will be used to achieve research objectives. Result shows PRPD normally distributed with skewness value still falling inside tolerance range of $-1 /+1$. We argue that the normal duration of activity can be estimated more quickly involving its normal PRPD. An estimator does not need to predict what the factors affecting the duration estimation, especially in the bidding/tender process. They only need the normal PRPD as a standard value, to estimate, to assess and to verify the normality level of actual duration for the purpose of project decision.
\end{abstract}

\section{Introduction}

The normal duration has an important role in the construction project in terms of the possibility of carrying out the project with reasonable effort. The normality of the activity duration may differ from one to another contractor even in the same project region/municipal. It is due to many factors/variables that affect each other, especially when estimating duration, which includes risk factor scheduling [1], unpredictable factors as a geographical factor [2], weather/climate [3], [4], etc. This condition provides an overview that the duration of each activity may change stochastically as a result of uncertainty-factors. The managers of Projects need to determine the scheduling time as quick as possible, as a requirement when bidding [5], [6], before conducting a technical analysis to achieve the predetermined duration. Therefore, they need to know the normal duration in order to conduct the project in the normal time span.

This study will propose a normal analysis of duration that refers to the normality of production rate per day (PRPD). It is based on Duration and PRPD relationships which basically have negative correlation or the bigger PRPD the smaller ND or vice versa. Based on this condition, the aims of this research are (i) estimating the normal duration of the project activities using the normal production rate per day (PRPD); and (ii) conducting the hypothesis testing for the PRPD normality of the project activities in South of Aceh region. Each contractor generates PRPD of activity that varies depending on the techniques and methods of work that are familiar with them. Although PRPD could differ from one to another contractor, we have a presumption that it will be normally distributed.

The method that is used to measure the normal duration is a central tendency approach of the mean parameters of the PRPD distribution that is based on the perceptions of the contractors in the project site. A total of 50 data have been collected from the respondents of the building contractors with small/medium qualification categories and its domiciled in South of Aceh region. The PRPD is the normally distributed if the statistical test results determining the null hypothesis is accepted or there is no reason to reject the null hypothesis. The null hypothesis in this study is the sample data of PRPD are not significantly different than its normal population, or this condition is said as the PRPD normal distribution.

In this study, we conclude that the duration of activities of the project in South of Aceh region is normally distributed. This result is in line with the result of Jiang's research where $93.72 \%$ of the 32 activities surveyed were normally distributed [7]. We argue the normal duration of the project activity can be estimated from its normal PRPD as well. We argue that the normal duration of the project activity can be estimated from its normal PRPD, and we also argue that duration estimation without involving its PRPD will lead to a less accurate of the project schedule. This is reinforcing Kannan's point of view that estimating the project

\footnotetext{
* Corresponding author: fachrurrazi@,unsyiah.ac.id
} 
implementation period requires a PRPD-based comprehensive approach to achieving the greatest possible completion of the project [8]. The formulation that can be used to analyse the normal duration (normally distributed) is the quantity take-off (QTO) of activity divided by the normal PRPD that should conform with normally distributed.

\section{State of the art}

The concept of estimated duration using the distribution has been known using PERT (Technical Review Evaluation Program) where the main objective is to create the project duration distribution. Based on the PERT Theory, project duration follows the normal distribution, with the mean being the result of time analysis based on the average duration of activity and variance [9].

The normal distribution is built based on two parameters, namely, mean $\mu$ and standard deviation $\sigma$. Mean $\mu$ is one of the centralized data measures, while the standard deviation $\sigma$ is the measure that describes the distribution of data [10]. The PRPD as a component of duration is a random variable that has a certain distribution. There are three statistical distribution models most commonly used in PRPD analysis, namely exponential distribution, normal distribution, and the lognormal distribution [7]. The development of the normal distribution is based on probability density functions (PDF), as shown in Formula (1).

$$
f\left(x, \mu, \sigma^{2}\right)=\frac{1}{\sqrt{2 \pi \sigma^{2}}} e^{-(x-\mu)^{2} / 2 \sigma^{2}}
$$

Where, $x$ represents a random variable, $\mu$ as the mean or expectation (it could be median or mode) of the normal distribution, and $\sigma^{2}$ as the variance of the random variable. The scientists have agreed that a random variable as a normal distribution requires a goodness of fit test by conducting hypothesis (as a mutually exclusive of population data that supported by the data sample) for evaluating of the two statements of the null hypothesis (Ho) and the alternative hypothesis (Hi) [11].

The number of the duration required to complete the project activity can be estimated using the formula (2). Where, D represents the duration of the activity; Q as the quantity of activity; and $\mathrm{P}$ as the production rate per day (PRPD) of activity.

$$
D=\frac{Q}{P}
$$

Production rate is the number of goods/works quantity that can be produced during a given period of time [7]. Production rate has a very important role in various fields, especially construction that has a number of activities in large quantities. We need to know the production rate to speed up estimation of the activity duration, especially in the main item of project activity requiring the on-site fabrication, such as formwork [12], rebar work [13], concrete work [14], etc.

\section{Method}

In this paper, we describe a technique for analysing the normal duration with the PRPD approach with normally distributed presumption, as the framework in Fig.1.

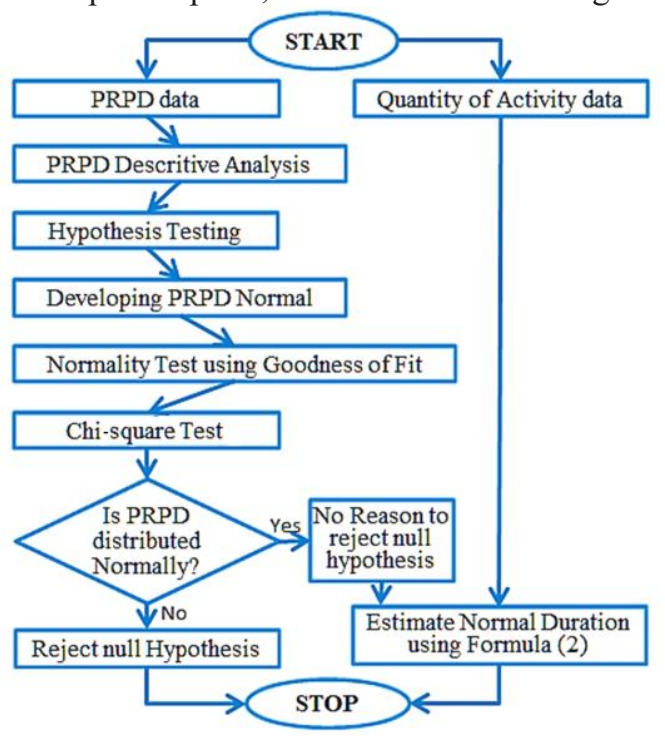

Fig. 1. Research Framework.

This research was conducted in South of AcehIndonesia. The subjects of this research are the building contractors, where the respondents are the director, or project manager, or project estimator, as it's characteristics in fig. 2.

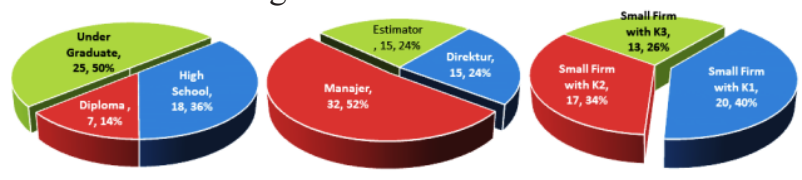

Fig. 2. Respondent Characteristic.

Hypothesis chi-squared goodness of fit tests [10] used to test the frequency of actual data and normal distribution frequency of population duration with values of level significance at level $\alpha=0.05$ (confidence level $95 \%)$; and discount factor $\mathrm{df}=\mathrm{n}-1(\mathrm{df}=49)$.

Ho: $\chi^{2}<\chi_{\text {critic }} \quad$ (There is no reason to reject the null hypothesis), this means that the PRPD sample data does not differ significantly from the normal population, or the PRPD is normally distributed.

Ho: $\chi^{2} \geq \chi_{\text {critic }} \quad$ (reject the null hypothesis and accepted the alternative hypothesis), this means that the PRPD sample data differ significantly from the normal population.

The Goodness of fit test is performed using the chisquare formula $\left(\chi^{2}\right)$, as shown in formula (3).

$$
\chi^{2}=\sum_{i=1}^{k} \frac{(O i-E i)^{2}}{E i}
$$

Where $O i$ is the observed frequency, k is categories, and $E i$ is the expected frequency.

We have collected 50 data for six of sub-activities which are from 2 main activities (main concrete column 
and practical column). These activities are concrete casting of main column (activity A), rebar work of main column (activity B), and formwork of main column (activity C), concrete casting of practical column (activity D), rebar work of practical column (activity E), and formwork of practical column (activity F). PRPD data is scattered as random variable, as shown in Fig. 3.

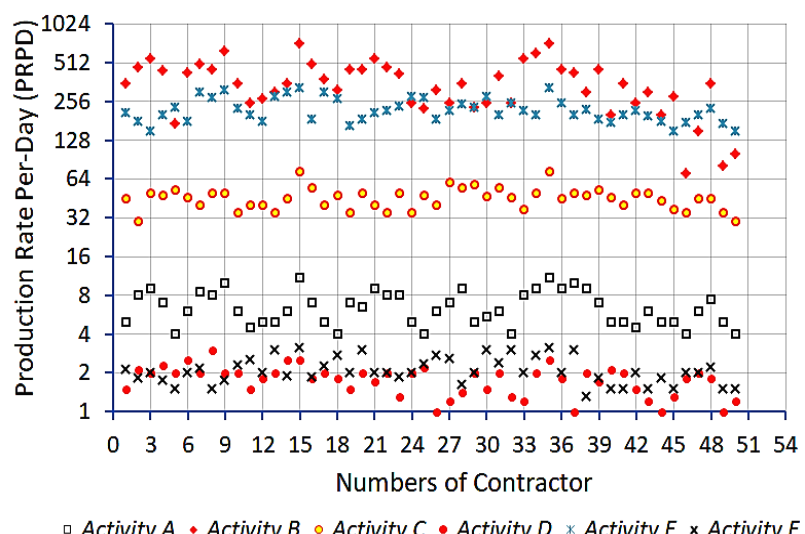

Fig. 3. PRPD data distribution of activity for 50 contractors.

\section{Result}

\subsection{Statistic descriptive analysis}

An important one to consider in performing a normality analysis, as characteristics additional of the centralized and variability of a data set, is a characterization of the skewness and kurtosis. The skewness is a measure of symmetry level, and Kurtosis is a measure relative tailed to a normal distribution (the proportion level of statistic variance in the data set distributed).

Table 1. Descriptive analysis for PRPD of project activities.

\begin{tabular}{|l|c|c|c|c|c|c|}
\hline \multirow{2}{*}{ Description } & \multicolumn{7}{|c|}{ Activity Code } \\
\cline { 2 - 7 } & A & B & C & D & E & F \\
\hline Mean & 6.58 & 362.10 & 45.78 & 1.79 & 222.16 & 2.11 \\
\hline Std. Error & 0.28 & 21.42 & 1.29 & 0.06 & 6.71 & 0.07 \\
\hline Median & 6 & 350 & 46 & 1.9 & 212.5 & 2 \\
\hline Mode & 5 & 350 & 50 & 2 & 200 & 2 \\
\hline Std. Dev. & 1.98 & 151.43 & 9.13 & 0.45 & 47.47 & 0.51 \\
\hline Variance & 3.93 & $22,930.7$ & 83.36 & 0.20 & $2,253.4$ & 0.26 \\
\hline Kurtosis & $(0.73)$ & $(0.07)$ & 1.55 & $(0.11)$ & $(0.53)$ & $(0.51)$ \\
\hline Skewness & 0.53 & 0.31 & 0.82 & 0.07 & 0.62 & 0.62 \\
\hline Range & 7 & 650 & 43 & 2 & 176 & 1.85 \\
\hline Minimum & 4 & 70 & 30 & 1 & 150 & 1.3 \\
\hline Maximum & 11 & 720 & 73 & 3 & 326 & 3.15 \\
\hline Sum & 329 & 18,105 & 2,289 & 89.5 & 11,108 & 105.6 \\
\hline Sample & 50 & 50 & 50 & 50 & 50 & 50 \\
\hline
\end{tabular}

The skewness values that using statistics descriptive analysis in Table 1, indicating un-symmetry of the probability of the mean of a random variable in a normal distribution. However, a hypothesis testing with a significance level of $95 \%$ needs to be conducted regarding enough evidence toward option to reject or no reject our presumption.

\subsection{Chi-Square Testing}

In this stage, we will calculate the chi-square using formula (3). The data frequency, as observed $(\mathrm{O} i)$, is based on the interval using bins that showing the maximum value of the interval scale, as shown in Table 2. The expectation $(E i)$ is the frequency of the PDF of the normal curve. The result of chi-square calculation (53.77) compared with chi-square significant (based on $\alpha 5 \%$ and df-49). The expectation analysis (Ei) is based on the cumulative distribution function (CDF) of standard normal distribution (SND). The cumulative value is $1(100 \%)$ for the random of the infinite variable, as shown in Table 2.

Table 2. Chi-Square Analysis for PRPD of activity A.

\begin{tabular}{|c|c|c|c|c|c|c|}
\hline \multirow{2}{*}{ Bins } & $\begin{array}{c}\text { Observed } \\
\text { Data }\end{array}$ & \multicolumn{3}{|c|}{ Normal Curve } & $\begin{array}{c}\text { Chi- } \\
\text { square }\end{array}$ \\
\cline { 2 - 6 } & Freq. & $\begin{array}{c}\text { Freq. } \\
\text { Cum. }\end{array}$ & Freq. & PDF & CDF & \\
\hline 0.00 & 0 & 0 & 0.02 & $0.05 \%$ & $0.05 \%$ & 0.02 \\
\hline 0.50 & 0 & 0 & 0.03 & $0.06 \%$ & $0.11 \%$ & 0.03 \\
\hline 1.00 & 0 & 0 & 0.07 & $0.14 \%$ & $0.24 \%$ & 0.07 \\
\hline 1.50 & 0 & 0 & 0.14 & $0.28 \%$ & $0.52 \%$ & 0.14 \\
\hline 2.00 & 0 & 0 & 0.26 & $0.52 \%$ & $1.05 \%$ & 0.26 \\
\hline 2.50 & 0 & 0 & 0.47 & $0.94 \%$ & $1.98 \%$ & 0.47 \\
\hline 3.00 & 0 & 0 & 0.78 & $1.57 \%$ & $3.55 \%$ & 0.78 \\
\hline 3.50 & 0 & 0 & 1.23 & $2.47 \%$ & $6.02 \%$ & 1.23 \\
\hline 4.00 & 6 & 6 & 1.82 & $3.64 \%$ & $9.66 \%$ & 9.58 \\
\hline 4.50 & 2 & 8 & 2.52 & $5.05 \%$ & $14.71 \%$ & 0.11 \\
\hline 5.00 & 11 & 19 & 3.28 & $6.57 \%$ & $21.28 \%$ & 18.13 \\
\hline 5.50 & 1 & 20 & 4.01 & $8.02 \%$ & $29.30 \%$ & 2.26 \\
\hline 6.00 & 7 & 27 & 4.60 & $9.20 \%$ & $38.50 \%$ & 1.26 \\
\hline 6.50 & 1 & 28 & 4.95 & $9.90 \%$ & $48.39 \%$ & 3.15 \\
\hline 7.00 & 5 & 33 & 5.00 & $10.00 \%$ & $58.39 \%$ & 0.00 \\
\hline 7.50 & 1 & 34 & 4.74 & $9.48 \%$ & $67.87 \%$ & 2.95 \\
\hline 8.00 & 5 & 39 & 4.22 & $8.44 \%$ & $76.30 \%$ & 0.14 \\
\hline 8.50 & 1 & 40 & 3.53 & $7.05 \%$ & $83.35 \%$ & 1.81 \\
\hline 9.00 & 6 & 46 & 2.77 & $5.53 \%$ & $88.88 \%$ & 3.78 \\
\hline 9.50 & 0 & 46 & 2.04 & $4.07 \%$ & $92.96 \%$ & 2.04 \\
\hline 10.00 & 2 & 48 & 1.41 & $2.81 \%$ & $95.77 \%$ & 0.25 \\
\hline 10.50 & 0 & 48 & 0.91 & $1.83 \%$ & $97.60 \%$ & 0.91 \\
\hline 11.00 & 2 & 50 & 0.56 & $1.11 \%$ & $98.71 \%$ & 3.75 \\
\hline 11.50 & 0 & 50 & 0.32 & $0.64 \%$ & $99.35 \%$ & 0.32 \\
\hline 12.00 & 0 & 50 & 0.17 & $0.34 \%$ & $99.69 \%$ & 0.17 \\
\hline 12.50 & 0 & 50 & 0.09 & $0.17 \%$ & $99.86 \%$ & 0.09 \\
\hline 13.00 & 0 & 50 & 0.04 & $0.08 \%$ & $99.94 \%$ & 0.04 \\
\hline 13.50 & 0 & 50 & 0.02 & $0.04 \%$ & $99.98 \%$ & 0.02 \\
\hline 14.00 & 0 & 50 & 0.01 & $0.02 \%$ & $99.99 \%$ & 0.01 \\
\hline Count: & 50 & & 50.00 & $99.99 \%$ & $\chi^{2}$ & 53.77 \\
\hline Mean: & 6.58 & & & & $\chi^{2}$ sig. & 66.34 \\
\hline Std. & 1.98 & & & & & \\
\hline & & & & & & \\
\hline
\end{tabular}

The results in Table 2 show $\chi^{2}<\chi^{2}$ sig. This result indicates that there is no reason to reject the null hypothesis. This means that the PRPD sample data does not differ significantly from the normal population (the PRPD is normally distributed).

Table 3. Type of PRPD distribution for each activity.

\begin{tabular}{|c|c|c|c|c|}
\hline Activity & Unit & Kind of Distribution & $\boldsymbol{\chi}^{\mathbf{2}}$ & $\boldsymbol{\chi}^{\mathbf{2}}$ sig. \\
\hline A & $\mathrm{M} 3$ & Normal Distribution & 53.77 & 66.34 \\
\hline B & $\mathrm{Kg}$ & Normal Distribution & 19.43 & 66.34 \\
\hline C & $\mathrm{M} 2$ & Normal Distribution & 52.19 & 66.34 \\
\hline D & $\mathrm{M} 3$ & Normal Distribution & 56.98 & 66.34 \\
\hline E & $\mathrm{Kg}$ & Normal Distribution & 28.56 & 66.34 \\
\hline F & $\mathrm{M} 2$ & Normal Distribution & 45.26 & 66.34 \\
\hline
\end{tabular}

We have analyzed a number of six activities having a normal distribution; despite the activities have different kurtosis and skewness. The point is that hypothesis 
testing is a must in order to know the type of distribution of the sample represents the population. The results of goodness fit test and chi-square value for the 6 activities are shown in Table 3.

\subsection{Distibution PRPD and Normal Duration}

Based on the calculation of $95 \%$ confidence interval of the PRPD normal distribution in South of AcehIndonesia, it can be determined that PRPD varies with range constraints as shown in Table 4.
Table 4. Interval of PRPD distribution for each activity.

\begin{tabular}{|c|c|r|r|c|}
\hline Activity & Unit & Mean & $\begin{array}{c}\text { Std. } \\
\text { Dev. }\end{array}$ & $\begin{array}{c}\text { 95\% Confidence } \\
\text { interval }\end{array}$ \\
\hline $\mathrm{A}$ & $\mathrm{M} 3$ & 6.58 & 1.98 & $2.69 \leq \mu \mathrm{A} \leq 10.47$ \\
\hline $\mathrm{B}$ & $\mathrm{Kg}$ & 362.10 & 151.43 & $65.30 \leq \mu \mathrm{B} \leq 658.90$ \\
\hline $\mathrm{C}$ & $\mathrm{M} 2$ & 45.78 & 9.13 & $27.89 \leq \mu \mathrm{C} \leq 63.67$ \\
\hline $\mathrm{D}$ & $\mathrm{M} 3$ & 1.79 & 0.45 & $0.90 \leq \mu \mathrm{D} \leq 2.68$ \\
\hline $\mathrm{E}$ & $\mathrm{Kg}$ & 222.16 & 47.47 & $129.12 \leq \mu \mathrm{E} \leq 315.20$ \\
\hline $\mathrm{F}$ & $\mathrm{M} 2$ & 2.11 & 0.51 & $1.12 \leq \mu \mathrm{F} \leq 3.10$ \\
\hline
\end{tabular}

Table 5. Estimating normal duration based on PRPD normal for 50 projects of the respondent.

\begin{tabular}{|c|c|c|c|c|c|c|c|c|c|c|c|c|}
\hline \multirow{4}{*}{ No } & \multicolumn{6}{|c|}{ Main Column } & \multicolumn{6}{|c|}{ Practical Column } \\
\hline & \multirow{2}{*}{\multicolumn{2}{|c|}{$\begin{array}{c}\text { Concrete Casting } \\
\text { Activity A }\end{array}$}} & \multirow{2}{*}{\multicolumn{2}{|c|}{$\begin{array}{c}\begin{array}{c}\text { Rebar work } \\
\text { Activity B }\end{array} \\
\text { Prod/day|: } \mathbf{3 6 2 . 1}\end{array}$}} & \multicolumn{2}{|c|}{$\begin{array}{l}\text { Formwork } \\
\text { Activity C }\end{array}$} & \multicolumn{2}{|c|}{$\begin{array}{l}\text { Concrete Casting } \\
\text { Activity D }\left(\mathrm{m}^{3}\right)\end{array}$} & \multicolumn{2}{|c|}{$\begin{array}{c}\text { Rebar work } \\
\text { Activity E (Kg) }\end{array}$} & \multicolumn{2}{|c|}{$\begin{array}{c}\text { Formwork } \\
\text { Activity F }\left(\mathrm{m}^{2}\right)\end{array}$} \\
\hline & & & & & Prod/day & 45.78 & Prod/day & 1.79 & Prod/day & 222.16 & Prod/day & $: 2.112$ \\
\hline & $\begin{array}{l}\text { Quantity } \\
\left(\mathrm{m}^{3}\right)\end{array}$ & $\begin{array}{c}\text { Normal } \\
\text { Duration } \\
\text { (days) }\end{array}$ & $\begin{array}{l}\text { Quantity } \\
(\mathrm{Kg})\end{array}$ & $\begin{array}{l}\text { Normal } \\
\text { Duration } \\
\text { (days) }\end{array}$ & $\begin{array}{l}\text { Quantity } \\
\left(\mathrm{m}^{2}\right)\end{array}$ & $\begin{array}{l}\text { Normal } \\
\text { Duration } \\
\text { (days) }\end{array}$ & $\begin{array}{l}\text { Quantity } \\
\left(\mathrm{m}^{3}\right)\end{array}$ & $\begin{array}{c}\text { Normal } \\
\text { Duration } \\
\text { (days) }\end{array}$ & $\begin{array}{l}\text { Quantity } \\
(\mathrm{Kg})\end{array}$ & $\begin{array}{c}\text { Normal } \\
\text { Duration } \\
\text { (days) }\end{array}$ & $\begin{array}{l}\text { Quantity } \\
\left(\mathrm{m}^{2}\right)\end{array}$ & $\begin{array}{c}\text { Normal } \\
\text { Duration } \\
\text { (days) }\end{array}$ \\
\hline 1 & 8.78 & 1.33 & 1494.17 & 4.13 & 62.72 & 1.37 & 1.06 & 0.59 & 193.79 & 0.87 & 8.15 & 3.86 \\
\hline 2 & 4.67 & 0.71 & 790.12 & 2.18 & 23.96 & 0.52 & 0.54 & 0.30 & 67.81 & 0.31 & 2.77 & 1.31 \\
\hline 3 & 5.88 & 0.89 & 702.07 & 1.94 & 52.92 & 1.16 & 0.96 & 0.54 & 183.45 & 0.83 & 7.38 & 3.50 \\
\hline 4 & 16.02 & 2.43 & 1902.86 & 5.26 & 154.87 & 3.38 & 1.50 & 0.84 & 310.79 & 1.40 & 21.58 & 10.22 \\
\hline 5 & 10.95 & 1.66 & 1182.92 & 3.27 & 3.17 & 0.07 & 1.03 & 0.58 & 249.26 & 1.12 & 0.31 & 0.15 \\
\hline 6 & 6.63 & 1.01 & 712.50 & 1.97 & 44.20 & 0.97 & 1.35 & 0.75 & 197.15 & 0.89 & 10.38 & 4.92 \\
\hline 7 & 6.78 & 1.03 & 1122.90 & 3.10 & 33.90 & 0.74 & 1.37 & 0.77 & 141.93 & 0.64 & 10.54 & 4.99 \\
\hline 8 & 8.92 & 1.36 & 1648.16 & 4.55 & 59.50 & 1.30 & 1.39 & 0.78 & 352.33 & 1.59 & 7.13 & 3.38 \\
\hline 9 & 2.51 & 0.38 & 291.56 & 0.81 & 25.10 & 0.55 & 0.75 & 0.42 & 211.44 & 0.95 & 3.75 & 1.78 \\
\hline 10 & 0.08 & 0.01 & 8.46 & 0.02 & 0.50 & 0.01 & 0.92 & 0.51 & 168.19 & 0.76 & 0.24 & 0.11 \\
\hline 11 & 37.21 & 5.66 & 3327.97 & 9.19 & 0.65 & 0.01 & - & - & & - & - & - \\
\hline 12 & - & - & - & - & - & - & 2.95 & 1.65 & 453.64 & 2.04 & 19.67 & 9.31 \\
\hline 13 & 17.09 & 2.60 & 2705.62 & 7.47 & 57.08 & 1.25 & 4.36 & 2.44 & 1240.56 & 5.58 & 33.44 & 15.83 \\
\hline 14 & 2.28 & 0.35 & 189.76 & 0.52 & 17.10 & 0.37 & 0.83 & 0.46 & 204.66 & 0.92 & 12.84 & 6.08 \\
\hline 15 & 49.25 & 7.48 & 13233.18 & 36.55 & 146.88 & 3.21 & 2.06 & 1.15 & 363.06 & 1.63 & 50.76 & 24.03 \\
\hline 16 & 2.75 & 0.42 & 382.91 & 1.06 & 22.00 & 0.48 & 0.11 & 0.06 & 20.11 & 0.09 & 0.85 & 0.40 \\
\hline 17 & 2.10 & 0.32 & 250.74 & 0.69 & 18.90 & 0.41 & 0.18 & 0.10 & 32.91 & 0.15 & 1.38 & 0.66 \\
\hline 18 & 1.43 & 0.22 & 129.32 & 0.36 & 19.00 & 0.42 & 0.17 & 0.09 & 35.18 & 0.16 & 5.20 & 2.46 \\
\hline 19 & 17.28 & 2.63 & 2783.23 & 7.69 & 67.20 & 1.47 & - & - & & - & - & - \\
\hline 20 & 6.33 & 0.96 & 958.36 & 2.65 & 82.29 & 1.80 & 2.58 & 1.44 & 504.84 & 2.27 & 45.87 & 21.72 \\
\hline 21 & 16.80 & 2.55 & 2705.92 & 7.47 & 65.33 & 1.43 & 0.16 & 0.09 & 29.22 & 0.13 & 0.82 & 0.39 \\
\hline 22 & 0.96 & 0.15 & 184.86 & 0.51 & 7.68 & 0.17 & 1.79 & 1.00 & 584.83 & 2.63 & 23.06 & 10.92 \\
\hline 23 & 0.60 & 0.09 & 42.01 & 0.12 & 3.60 & 0.08 & 1.10 & 0.61 & 246.10 & 1.11 & 8.04 & 3.81 \\
\hline 24 & 17.28 & 2.63 & 3181.93 & 8.79 & 50.40 & 1.10 & 1.60 & 0.89 & 233.05 & 1.05 & 6.14 & 2.91 \\
\hline 25 & 14.76 & 2.24 & 2277.72 & 6.29 & 171.81 & 3.75 & 1.66 & 0.92 & 713.68 & 3.21 & 30.10 & 14.25 \\
\hline 26 & - & - & - & - & - & - & 2.49 & 1.39 & 522.74 & 2.35 & 19.14 & 9.06 \\
\hline 27 & 7.00 & 1.06 & 1659.91 & 4.58 & 112.00 & 2.45 & 3.45 & 1.93 & 1029.60 & 4.63 & 53.04 & 25.11 \\
\hline 28 & 3.89 & 0.59 & 94.80 & 0.26 & 11.67 & 0.25 & 0.48 & 0.27 & 256.19 & 1.15 & 10.26 & 4.86 \\
\hline 29 & 37.21 & 5.66 & 3327.93 & 9.19 & 186.05 & 4.06 & 3.45 & 1.93 & 626.96 & 2.82 & 46.05 & 21.80 \\
\hline 30 & 4.38 & 0.67 & 441.93 & 1.22 & 35.00 & 0.76 & 3.41 & 1.91 & 620.76 & 2.79 & 22.72 & 10.76 \\
\hline 31 & 1.92 & 0.29 & 478.21 & 1.32 & 38.40 & 0.84 & 0.81 & 0.45 & 242.26 & 1.09 & 12.48 & 5.91 \\
\hline 32 & 0.95 & 0.14 & 172.45 & 0.48 & 25.20 & 0.55 & - & - & & - & - & - \\
\hline 33 & 0.58 & 0.09 & 124.58 & 0.34 & 15.36 & 0.34 & - & - & & - & - & - \\
\hline 34 & 4.32 & 0.66 & 1494.10 & 4.13 & 86.40 & 1.89 & 3.25 & 1.81 & 940.63 & 4.23 & 49.92 & 23.64 \\
\hline 35 & 26.60 & 4.04 & 6256.08 & 17.28 & 85.40 & 1.87 & 8.91 & 4.98 & 2774.90 & 12.49 & 269.62 & 127.66 \\
\hline 36 & 0.08 & 0.01 & 8.46 & 0.02 & 0.50 & 0.01 & 0.92 & 0.51 & 168.19 & 0.76 & 0.24 & 0.11 \\
\hline 37 & 0.13 & 0.02 & 9.75 & 0.03 & 1.35 & 0.03 & 0.45 & 0.25 & 78.75 & 0.35 & 1.81 & 0.85 \\
\hline 38 & 0.08 & 0.01 & 8.46 & 0.02 & 0.50 & 0.01 & 0.92 & 0.51 & 168.19 & 0.76 & 0.24 & 0.11 \\
\hline 39 & 0.99 & 0.15 & 220.76 & 0.61 & 9.90 & 0.22 & 0.15 & 0.08 & 38.02 & 0.17 & 3.22 & 1.52 \\
\hline 40 & 2.52 & 0.38 & 434.41 & 1.20 & 16.85 & 0.37 & 1.00 & 0.56 & 189.87 & 0.85 & 161.95 & 76.68 \\
\hline 41 & 3.86 & 0.59 & 326.78 & 0.90 & 77.28 & 1.69 & 0.35 & 0.20 & 74.59 & 0.34 & 5.46 & 2.59 \\
\hline 42 & 0.13 & 0.02 & 9.75 & 0.03 & 1.35 & 0.03 & 0.45 & 0.25 & 78.75 & 0.35 & 1.86 & 0.88 \\
\hline 43 & 0.13 & 0.02 & 9.75 & 0.03 & 1.35 & 0.03 & 0.45 & 0.25 & 78.75 & 0.35 & 1.86 & 0.88 \\
\hline 44 & 0.13 & 0.02 & 9.75 & 0.03 & 1.35 & 0.03 & 0.45 & 0.25 & 78.75 & 0.35 & 1.86 & 0.88 \\
\hline 45 & 0.13 & 0.02 & 9.75 & 0.03 & 1.35 & 0.03 & 0.45 & 0.25 & 78.75 & 0.35 & 1.86 & 0.88 \\
\hline 46 & 3.38 & 0.51 & 562.35 & 1.55 & 15.00 & 0.33 & 0.33 & 0.18 & 72.54 & 0.33 & 1.71 & 0.81 \\
\hline 47 & 16.92 & 2.57 & 2373.82 & 6.56 & 225.60 & 4.93 & 1.22 & 0.68 & 177.56 & 0.80 & 18.72 & 8.86 \\
\hline 48 & 0.13 & 0.02 & 9.75 & 0.03 & 1.35 & 0.03 & 0.45 & 0.25 & 78.75 & 0.35 & 1.86 & 0.88 \\
\hline 49 & 0.13 & 0.02 & 9.75 & 0.03 & 1.35 & 0.03 & 0.45 & 0.25 & 78.75 & 0.35 & 1.86 & 0.88 \\
\hline 50 & 0.13 & 0.02 & 9.75 & 0.03 & 1.35 & 0.03 & 0.45 & 0.25 & 78.75 & 0.35 & 1.86 & 0.88 \\
\hline
\end{tabular}


Based on normal PRPD can be determined normal duration by using equation (2). We estimate the normal duration of 50 contractor respondents by using their project quantity take-off (QTO) as shown in Table 5. Normal values of this duration can be used to review and verify the actual duration of their project. This is an opportunity for another researcher for future research.

\section{Discussion}

\subsection{Skewness of the normal distribution}

The skewness value shown in Table 1 indicates that the distribution has an asymmetry of the normal distribution. The trade-off between the normal distribution and nonnormal distribution is illustrated by how far the skewness value of the observational data from zero skewness. The result of the goodness of fit testing in this research shows that the highest skewness value $(0.82)$, on activity $\mathrm{C}$ of this research, indicates that the distribution is a normal distribution. This condition is in line with statement that skewness values falling outside the range of -1 to +1 indicate a substantially skewed distribution [15].

\subsection{Normal distribution of PRPD}

The activities duration is a random variable that caused by PRPD changing stochastically and uncertainty in conducting day to day project activity. Project managers in South of Aceh region could quickly determine the duration of activity by referring to this research. This study has been able to determine the average normal duration of any activity that is based on the mean PRPD normal. An illustration of the normal duration pattern of activity-A based on the observed of the PRPD frequency distribution is shown in Fig. 4. Although skewness caused by the largest mode in PRPD of $5 \mathrm{~m}^{3} /$ day compared to the average PRPD of $6.58 \mathrm{~m}^{3} /$ day, a project manager can choose a PRPD alternative within the range from 5 to $6.58 \mathrm{~m}^{3} /$ day as a PRPD option.

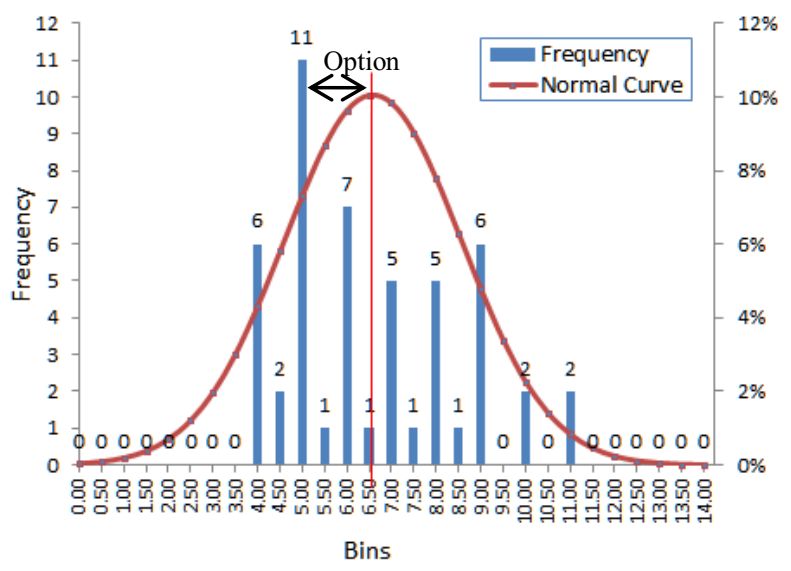

Fig. 4. Normal Distribution of Concrete Casting Activity.

This study shows all the activities surveyed (100\% of 6 activities) have a normal distribution as a result of the hypothesis testing in this study. It is consistent with the result of Jiang's research, where $93.72 \%$ of the 32 activities surveyed were normally distributed [7].

\subsection{Estimating the normal duration using PRPD}

The estimating duration of activity can be conducted using several techniques. The formula (2) shows that the estimating duration technique can be determined by assessing the PRPD value of the activity although there is a difference of the activity quantity of each project. This is the practical technique that can be used by the project manager as technical justification to develop a project schedule. This is in line with the opinions of Liu which provide an overview of the Production rate of activity is an important stage in the development of the schedule and project management [16]. The model using the PRPD approach to estimation of duration in the captive process is recommended if the available resources are unlimited [7]. The approach is also very easy to implemented using current software [17]. The estimation result of duration especially in South of Aceh region is shown in Table 5 .

\section{Conclusion}

This study performs a normal duration analysis based on a normal PRPD. The normal PRPD is obtained from a centralized tendency of the mean of a normally distributed PRPD. The descriptive statistics analysis generates the non-zero skewness and kurtosis which allows the distribution of PRPD not normally distributed or un-symmetry of the distribution curve. Even though, the hypothesis testing using chi-square result shows that the six of activities in this research (Activity of A, B, C, D, E, F) show PRPD normally distributed. The normal PRPD is successful of $6.58 \mathrm{~m}^{3}, 362.10 \mathrm{~kg}, 45.7 \mathrm{~m}^{2}, 1.79$ $\mathrm{m}^{3}, 222.16 \mathrm{~kg}$, and $2.11 \mathrm{~m}^{2}$, as shown in Table 4 .

This condition shows that the project estimator does not need to predict what the factors affecting the duration estimation, especially in the bidding/tender process. They only need the normal PRPD regarding estimate the normal duration of the project activity. Normal PRPD values can be used as a standard value to assess and to verify the normality level of actual duration for the purpose of project decision (actual duration could be upper or lower of the normal duration).

We realize that this paper has been given a lot of involvement and participation from parties. For that, the authors would like to thank for PI-Tech teamwork, staff of the Construction Engineering Management (CEM) Laboratory - Syiah Kuala University, and the contractors in the south of Aceh-Indonesia

\section{References}

1. Sigmund, Z. \& Radujković, M. Risk Breakdown Structure for Construction Projects on Existing Buildings. Procedia - Soc. Behav. Sci. 119, 894 901 (2014).

2. Fachrurrazi, Husin, S., Tripoli \& Mubarak. Neural Network for the Standard Unit Price of the

\footnotetext{
* Corresponding author: fachrurrazi@unsyiah.ac.id
} 
Building Area. in Procedia Engineering 171, 282293 (Elsevier, 2017).

3. Marzoughi, F., Arthanari, T. \& Askarany, D. A decision support framework for estimating project duration under the impact of weather. Autom. Constr. 87, 287-296 (2018).

4. Sambasivan, M. \& Soon, Y. W. Causes and effects of delays in Malaysian construction industry. Int. $J$. Proj. Manag. 25, 517-526 (2007).

5. Fachrurrazi, Away, Y. \& Husin, S. The weights detection of multi-criteria by using Solver. Int. J. Electr. Comput. Eng. 7, 858-868 (2017).

6. Fachrurrazi, Saiful Husin, Munirwansyah \& Husaini. The Subcontractor Selection Practice using ANN-Multilayer. Int. J. Technol. 8, 761 (2017).

7. Jiang, Y. \& Wu, H. Production rates of highway construction activities. in International Journal of Construction Education and Research 3, 81-98 (2007).

8. Kannan, S. R. \& Senthil, R. Production based scheduling method for linear construction in road projects. KSCE J. Civ. Eng. 18, 1292-1301 (2014).

9. Hajdu, M. \& Bokor, O. The Effects of Different Activity Distributions on Project Duration in PERT Networks. Procedia - Soc. Behav. Sci. 119, 766775 (2014)
10. Voinov, V., Nikulin, M. \& Balakrishman, N. ChiSquared Goodness of Fit Tests with Applications. (Academic Press, 2013).

11. Fachrurrazi. The end user requirement for project management software accuracy. Int. J. Electr. Comput. Eng. 81, 1112-1121 (2018)

12. Proverbs, D. G., Holt, G. D. \& Olomolaiye, P. O. A comparative evaluation of planning engineers' formwork productivity rates in European construction. Build. Environ. 33, 181-187 (1998)

13. Ix, I. \& Congress, W. The Productivity of Steel Reinforcement Placement in Australian Construction. 1-9 (2007).

14. Freeman Price, A. D. An evaluation of production output for in situ concrete work. (C) Andrew David Freeman Price, 1986).

15. Hair, J. F., Black, W. C., Babin, B. J. \& Anderson, R. E. Multivariate Data Analysis. Vectors (2014).

16. Liu, L., Liu, Y. \& Tang, Y. Production Rate Determination for Linear Construction Projects Based on Linear Scheduling Method. Int. J. Smart Home 10, 143-152 (2016).

17. Chong, W. K., Lee, S.-H. \& O'Connor, J. Estimating Highway Construction Production Rates during Design: Elements of a Useful Estimation Tool. Leadersh. Manag. Eng. 11, 258-266 (2011). 